\title{
Bone marrow mononuclear cells attenuate fibrosis development after severe acute kidney injury
}

\author{
Patricia Semedo ${ }^{1,4}$, Cassiano Donizetti-Oliveira ${ }^{1,4}$, Marina Burgos-Silva ${ }^{1,4}$, Marco Antonio Cenedeze , \\ Denise Maria Avancini Costa Malheiros ${ }^{2}$, Alvaro Pacheco-Silva ${ }^{1}$ and Niels Olsen Saraiva Câmara ${ }^{1,3}$
}

One of the early phases that lead to fibrosis progression is inflammation. Once this stage is resolved, fibrosis might be prevented. Bone marrow mononuclear cells (BMMCs) are emerging as a new therapy for several pathologies, including autoimmune diseases, because they enact immunosuppression. In this study we aimed to evaluate the role of BMMC administration in a model of kidney fibrosis induced by an acute injury. C57BI6 mice were subjected to unilateral severe ischemia by clamping the left renal pedicle for $1 \mathrm{~h}$. BMMCs were isolated from femurs and tibia, and after $6 \mathrm{~h}$ of reperfusion, $1 \times 10^{6}$ cells were administrated intraperitoneally. At $24 \mathrm{~h}$ after surgery, treated animals showed a significant decrease in creatinine and urea levels when compared with untreated animals. Different administration routes were tested. Moreover, interferon (IFN) receptor knockout BMMCs were used, as this receptor is necessary for BMMC activation. Labeled BMMCs were found in ischemic kidney on FACS analysis. This improved outcome was associated with modulation of inflammation in the kidney and systemic modulation, as determined by cytokine expression profiling. Despite non-amelioration of functional parameters, kidney mRNA expression of interleukin (IL)- 6 at 6 weeks was lower in BMMC-treated animals, as were levels of collagen 1, connective tissue growth factor (CTGF), transforming growth factor- $\beta$ (TGF- $\beta$ ) and vimentin. Protective molecules, such as IL-10, heme oxygenase 1 (HO-1) and bone morphogenetic 7 (BMP-7), were increased in treated animals after 6 weeks. Moreover, Masson and Picrosirius red staining analyses showed less fibrotic areas in the kidneys of treated animals. Thus, early modulation of inflammation by BMMCs after an ischemic injury leads to reduced fibrosis through modulation of early inflammation.

KEYWORDS: mesenchymal stem cell; acute kidney injury; ischemia-reperfusion injury; fibrosis; inflammation; bone marrow

Laboratory Investigation (2010) 90, 685-695; doi:10.1038/labinvest.2010.45; published online 22 March 2010

Despite available strategies for ameliorating acute kidney injury (AKI) outcomes, mortality rates still range from 50 to $80 \%$, especially in patients in intensive care units and after kidney transplantation. ${ }^{1}$ In addition, AKI is a major antigenindependent factor closely implicated in long-term graft dysfunction, namely chronic allograft nephropathy (CAN). ${ }^{2}$

The pathogenesis of this interstitial fibrosis and tubular atrophy is multi-factorial, but it seems that early ischemic events represent a start point. ${ }^{3,4}$ A single AKI may lead to expression of several pro-inflammatory and fibrotic genes that may incite fibrosis in the kidney. ${ }^{5}$
Epithelial-to-mesenchymal transition (EMT) has an important role in renal fibrosis development. The orchestrated multi-step differentiation of tubular epithelial cells in activated myofibroblasts leads to collagen deposition and a change in tissue architecture. ${ }^{6-9}$ Transforming growth factor- $\beta$ (TGF- $\beta$ ) and connective tissue growth factor (CTGF) have crucial roles in promoting these events. ${ }^{10,11}$

Once fibrosis has been established, few approaches are available to retard the functional deterioration of graft organs. Most of the studies so far have analyzed prevention rather than reversal of renal disease. ${ }^{12}$ However, blockage

\footnotetext{
${ }^{1}$ Experimental and Clinical Immunology Laboratory, Division of Nephrology, Universidade Federal de São Paulo, Escola Paulista de Medicina, São Paulo, Brazil;

${ }^{2}$ Department of Pathology, Universidade de São Paulo, São Paulo, Brazil and ${ }^{3}$ Laboratory of Transplantation Immunobiology, Department of Immunology,

Universidade de São Paulo, São Paulo, Brazil

Correspondence: Dr NOS Câmara, MD, Department of Immunology, Institute of Biomedical Science IV, Universidade de São Paulo, Rua Professor Lineu Prestes, 1730, 05508-900 São Paulo, SP, Brazil.

E-mail: niels@icb.usp.br

${ }^{4}$ These authors contributed equally to this work.

Received 9 February 2009; revised 5 October 2009; accepted 10 November 2009
} 
of the renin angiotensin system and administration of mycophenolate mofetil, as well as bone morphogenetic 7 (BMP-7) and hepatocyte growth factor (HGF) therapies, are good options for better outcomes. ${ }^{13-20}$

Recently, adult stem cells have emerged as a new therapy for several diseases. ${ }^{21-23}$ Of all the adult stem cells in the body, stem cells from bone marrow seem to be most attractive for therapy because they are easily isolated. There are two types of stem cells in bone marrow: hematopoietic stem cells and mesenchymal stem (stromal) cells. Actually, an inflammatory milieu is necessary for adult stem cell activation, to secrete several trophic factors, with regenerative and remodeling properties. Interferon $-\gamma$ (IFN- $\gamma$ ) is needed for indolamine 2,3 secretion by adult stem cell, which can exert an effect in inhibition of T-cell proliferation, thereby immunomodulating inflammation. ${ }^{24,25}$ In nephrology, stem cell therapy was associated with better outcomes for AKI in experimental models. ${ }^{26-29}$ Whole bone marrow administration in a remnant model also showed improvement in progression of chronic kidney disease. ${ }^{30}$

In this study we report that administration of BMMCs attenuates renal fibrosis 6 weeks after a severe event of AKI. Furthermore, we provide evidence that immune modulation of early inflammatory events might be one mechanism behind BMMC-mediated protection.

\section{MATERIALS AND METHODS Animal Model}

Female C57BL/6J mice, 8 weeks of age from CEDEME (Federal University of São Paulo, São Paulo, Brazil), underwent $60 \mathrm{~min}$ of unilateral ischemia or sham surgery and were then monitored for $24 \mathrm{~h}$ and at 6 weeks after ischemia. In brief, doses of ketamine $150 \mathrm{mg} / \mathrm{kg}$ and xylazine $10 \mathrm{mg} / \mathrm{kg}$ were given intraperitoneally. Mice underwent abdominal incisions and their right renal pedicle was bluntly dissected. A microvascular clamp (Rocca, São Paulo, Brazil) was placed on the right renal pedicle for $60 \mathrm{~min}$. Animal temperature was maintained close to $37^{\circ} \mathrm{C}$. Animals were monitored and maintained for $24 \mathrm{~h}$ and 6 weeks before killing. Sham animals underwent the same surgical procedure without clamping of the renal artery.

\section{Isolation of BMMCs}

Male C57BL/6J mice $(n=5)$ of $4-5$ weeks were killed by an overdose of anesthetics. Tibias and femurs were removed and flushed with phosphate-buffered saline (PBS) under sterile conditions. Whole bone marrow cells were washed twice with PBS and red blood cells were lysed with $0.84 \%$ chloride ammonium buffer. Again, these cells were washed three times with PBS. This fraction of cells, without red blood cells, is the BMMC. Cells were counted in Neubauer's chamber. BMMCs from receptor IFN knockout animal were isolated in the same way.

\section{BMMC Immunophenotyping}

In brief, a cell suspension $\left(1 \times 10^{5}\right.$ cells $)$ of BMMC was incubated for $40 \mathrm{~min}$ in saturating concentrations of the antibodies CD34-FITC, CD105-FITC, CD31-FITC, CD73-PE, CD117-PE and CD44-PE (BD Biosciences Pharmingen, San Diego, CA, USA). After three washes, the cells were centrifuged at $200 \mathrm{~g}$ for $5 \mathrm{~min}$ and resuspended in ice-cold PBS. Cell fluorescence was evaluated using a flow cytometer (FACSCanto; Becton Dickinson, Franklin Lakes, NJ, USA).

\section{Cell Treatment}

After $6 \mathrm{~h}$ of surgery, some animals received BMMCs intraperitoneally or endovenously. Nearly $1 \times 10^{6}$ cells were administered to each animal.

\section{Cell Labeling for Tracking Assay}

The BMMCs were incubated with Qtracker $585 \mathrm{~nm}$ (Invitrogen, CA, USA) as recommended by the manufacturer. One population of Qtracker-labeled cells was analyzed using flow cytometer (FACSCanto; BD Biosciences). These cells were injected into the orbital vein or intraperitoneally in four animals. These animals were killed at $24 \mathrm{~h}$ after severe IR. Kidneys, spleen and lungs were passed through a $70 \mu \mathrm{M}$ cell strainer (Becton Dickinson). This was followed by Histopaque gradient separation $(d=1077 \mathrm{mg} / \mathrm{l}$; Sigma), and centrifugation at $400 \mathrm{~g}$ for $30 \mathrm{~min}$ at room temperature. The cells recovered in the Histopaque/buffer interface were subjected to flow cytometry (FACSCanto; Becton Dickinson) viewed through a PE filter set.

\section{Assessment of Renal Function}

Serum creatinine was measured by Jaffe's modified method. Serum urea was measured using a Labtest Kit (Labtest, Minas Gerais, Brazil). Urine was collected weekly and a ratio of urine protein/urine creatinine was used to determine proteinuria (measured by Labtest Kit).

\section{Morphology}

Kidneys were obtained 6 weeks after ischemia and analyzed using Masson and Picrosirius red staining. Renal area was measured using ImageJ program at a magnification of $\times 4$. For histological examinations, kidneys were fixed with $10 \%$ buffered formaldehyde for $24 \mathrm{~h}$, washed with $70 \%$ ethanol for $24 \mathrm{~h}$ and then embedded in paraffin. Sections were cut with a thickness of $4 \mu \mathrm{m}$. A blinded reviewer compared ischemic kidneys, treated or not, with sham-operated kidneys. To evaluate the extent of renal interstitial expansion, the fraction of renal cortex occupied by interstitial tissue staining positively for extracellular matrix components (collagen) was quantitatively evaluated in Masson-stained sections by a point-counting technique in consecutive microscopic fields at a final magnification of $\times 100$ under a 176-point grid. Picrosirius red staining was measured at a magnification of $\times 20$ using the NIS Elements program of Nikon microscopy, with at least 10 consecutives fields. 


\section{Real Time PCR}

Kidney samples were quickly frozen in liquid nitrogen. Total RNA was isolated using the TRIzol Reagent (Invitrogen, Carlsbad, CA) and RNA concentrations were determined by Nanodrop. First-strand cDNAs were synthesized using the MML-V reverse transcriptase (Promega, Madison, WI, USA). Reverse transcriptase polymerase chain reaction (PCR) was performed using TaqMan probes. Sequence Detection Software 1.9 (SDS) was used for analysis. mRNA expression was normalized to HPRT abundance. The values are expressed relative to a reference sample (the calibrator): sham operated samples. The Ct (threshold cycle) for the target gene and the $\mathrm{Ct}$ for the internal control were determined for each sample. Samples were run in triplicate. The relative expression of mRNA was calculated by $2^{-\Delta \Delta C T}$. All the experimental samples are expressed as an $\mathrm{n}$-fold difference relative to the calibrator.

\section{Bioplex}

A Bio-Plex mouse Th1/Th2-Plex cytokine assay kit (Bio-Rad Laboratories, Hercules, CA, USA) was used to test samples for the presence of eight cytokines: interleukin (IL)-2, IL-4, IL-5, IL-10, IL-12(p70), granulocyte macrophage colony-stimulating factor (GM-CSF), tumor necrosis factor (TNF)- $\alpha$ and IFN- $\gamma$. The assay was read on the Bio-Plex suspension array system, and the data were analyzed using Bio-Plex Manager software version 4.0. Standard curves ranged from 1.95 to $32000 \mathrm{pg} / \mathrm{ml}$.

\section{Immunohistochemistry}

Localization of $\alpha$-SMA (diluted 1:600; M0851, DAKO), vimentin (diluted 1:600, DAKO) and FSP-1 (diluted 1:600, A5114, DAKO) were performed in paraffin-embedded sections. Previously, the slides were deparaffinized, rehydrated and submitted to Tris-EDTA pH 9 antigen retrieval solution at $95^{\circ} \mathrm{C}$. The endogenous peroxidase activity was blocked with $3 \%$ hydrogen peroxide, and sections were also blocked with Protein Block Solution (DAKO). Slides were then incubated with primary antibody or negative control reagent, followed by incubation with the labeled polymer Envision (DAKO), using two sequential 30 -min incubations at room temperature. Staining is completed by a $1-3 \mathrm{~min}$ incubation with $3,3^{\prime}$-diaminobenzidine $(\mathrm{DAB})+$ substrate-chromogen, which results in a browncolored precipitate at the antigen site. Hematoxilin counterstaining was performed.

\section{Statistical Analysis}

Data were expressed as mean \pm s.d. Analysis of variance (ANOVA) and Fisher's least-significant difference test were used to compare means of multiple groups statistically. For paired data, Student's $t$-test was used. Statistical significance was set at $P<0.05$.

\section{RESULTS}

\section{BMMC Immunophenotyping}

BMMCs were characterized using some markers and analyzed by FACS. As these cells correspond to nearly all cells from bone marrow, they were positive for several markers (Figure 1a-f). CD34 and CD117 are hematopoeitic markers. CD73, CD44 and CD105 positives are indicative of mesenchymal stem cells (MSCs). CD31 is a PECAM-1 molecule well expressed in endothelial cells. Therefore, it is possible to observe that $\mathrm{BMMC}$ is composed of all progenitors present in bone marrow.

\section{Cell Therapy Induced an Improvement in Renal Parameters at $\mathbf{2 4} \mathrm{h}$ and BMMCs are Present in Ischemic Kidney after IP Administration}

After $24 \mathrm{~h}$ of kidney reperfusion (and $18 \mathrm{~h}$ after treatment with mononuclear cells from bone marrow), creatinine and urea functional parameters showed significant amelioration in treated animals (Figure $2 \mathrm{a}$ and $\mathrm{b}$ ), independent of their administration route as well as if BMMCs were from IFN receptor knockout donors. Moreover, for tracking these cells at ischemic kidney, lung and spleen, BMMCs were labeled with Qtracker. In FACS charter, it is possible to observe that BMMC labeling is intense and all cells have been labeled (Figure 2c). Tracking these cells by PE filter set, we found that endovenous administration led to an accumulation of cells in the lung. Moreover, just on IP administration, BMMC could be found in ischemic kidney (Figure 2d).

\section{Treatment with BM Leads to Downregulation of Cytokine Expression at $\mathbf{2 4} \mathrm{h}$ on Renal Tissue and Systemic Modulation}

BMMC treatment led to downregulation of Th1 cytokines (IL-6) in kidneys after $24 \mathrm{~h}$; nevertheless, levels of TNF- $\alpha$ did not differ between groups. On the other hand, IL-10, a Th2 cytokine, was increased after treatment (Figure 3).

However, BMMCs from receptor IFN KO did not change renal cytokines profile. IL-6 mRNA expression was elevated in untreated animals. In addition, IL-4 is less expressed in treated BMMCs from receptor IFN KO when compared with untreated animals (Figure 3).

Systemic modulation was also observed, as ischemia and reperfusion injury (IRI) leads to change in the systemic cytokines balance. From cytokines analyzed by Bioplex, IL-12(p70), IL-10, IL-5 and TNF- $\alpha$ were decreased in serum of animals treated with BMMCs (Figure 3). IFN- $\gamma$ and GM-CSF serum levels did not change. IL-2 and IL-4 could not be measured with this assay.

\section{Functional Parameters after 6 Weeks}

In necropsy, gross macroscopic histology revealed that the kidneys of BMMC-treated animals were not reduced in size similar to the kidneys of untreated animals (Figure $4 \mathrm{a}$ and $\mathrm{b}$ ). Renal area was measured and revealed that ischemic kidneys from treated animals are bigger in size than untreated ones (Figure 4c). 

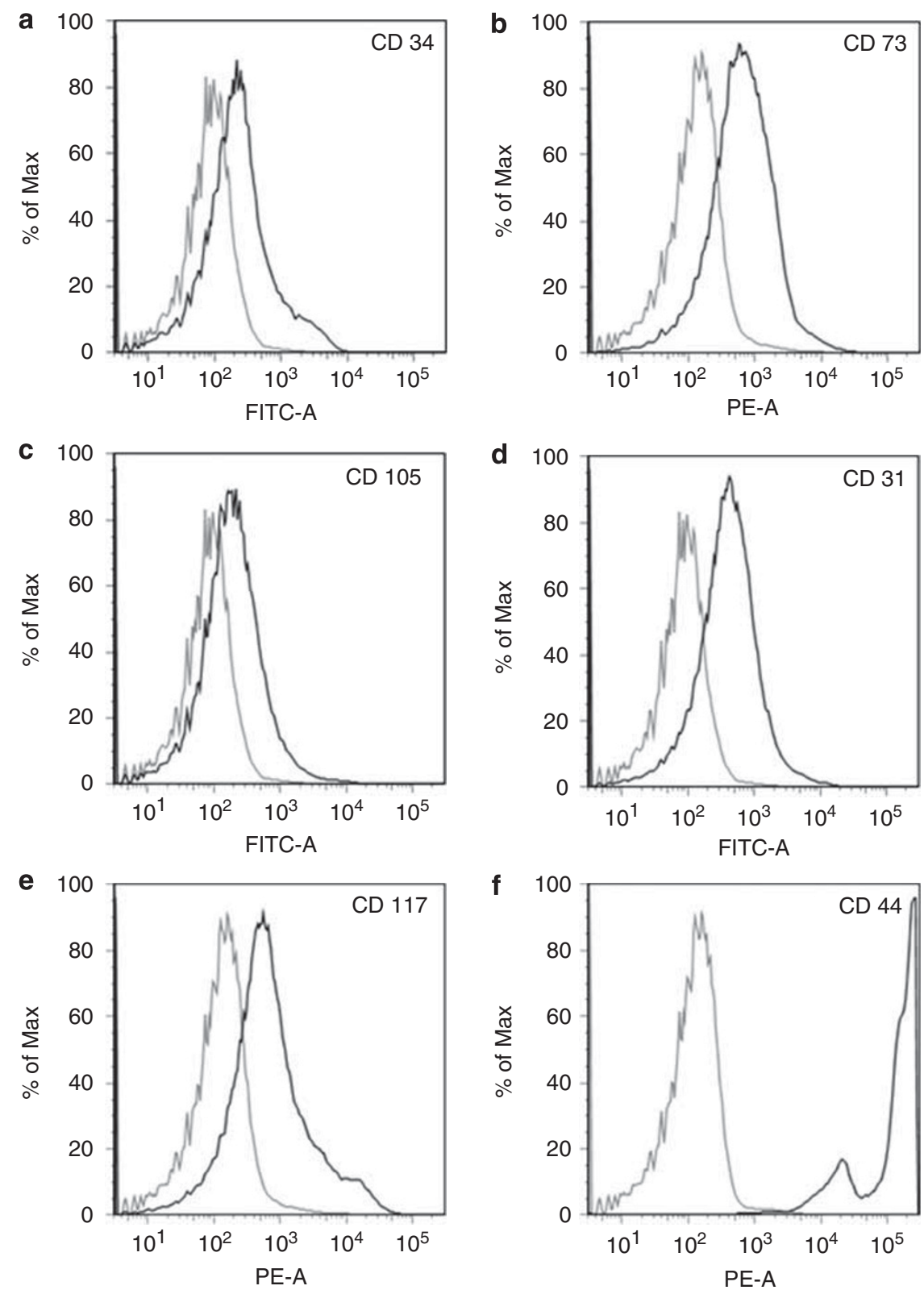

Figure 1 . BMMC immunophenotyping. BMMCs were isolated and labeled for CD34 (a), CD73 (b), CD105 (c), CD31 (d), CD117 (e) and CD44 (f). BMMC population is positive for all markers, more significantly for CD44.

In contrast to $24 \mathrm{~h}$ functional results, serum creatinine levels were not changed with treatment after 6 weeks. However, animals subjected to severe AKI after 6 weeks showed higher levels of serum creatinine when compared with sham animals (Figure 4d).

Masson Trichrome's staining revealed that the kidneys of BMMC-treated animals subjected to severe ischemia and reperfusion injury showed less fibrosis when compared with kidneys of untreated animals. This pattern was also observed after Picrosirius red staining (Figure $4 \mathrm{e}$ and $\mathrm{f}$ ).

Urine analysis showed that untreated animals developed proteinuria when compared with sham animals. And besides, BMMC-treated animals have an attenuated proteinuria when compared with untreated animals (Figure $4 \mathrm{~g}$ ).
Treatment with BM Leads to Downregulation of Cytokine and Pro-Fibrotic Molecules at 6 Weeks

After 6 weeks, the expression of IL- 6 and TNF- $\alpha$ in the kidneys of BM-treated animals was decreased when compared with the untreated animals (Figure $5 \mathrm{a}$ and b). IL-10, an anti-inflammatory cytokine, has increased mRNA levels in the kidney tissues of BMMC-treated animals (Figure 5c).

mRNA expression of collagen type 1, CTGF, TGF- $\beta$ and vimentin also provided evidence of decreased fibrosis in the kidneys of BMMC-treated animals (Figure $5 \mathrm{~d}-\mathrm{g}$ ), although the reduction in TGF- $\beta$ mRNA levels was not significant. On the other hand, protective molecules such as heme oxygenase 1 (HO-1) and BMP-7 were expressed at higher levels in the kidneys 
a

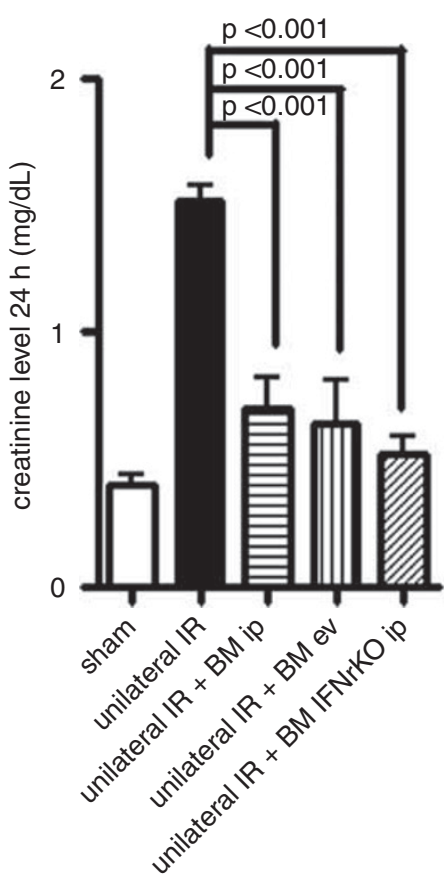

d $24 \mathrm{~h}(\%)$
Kidney
Spleen
Lung

b

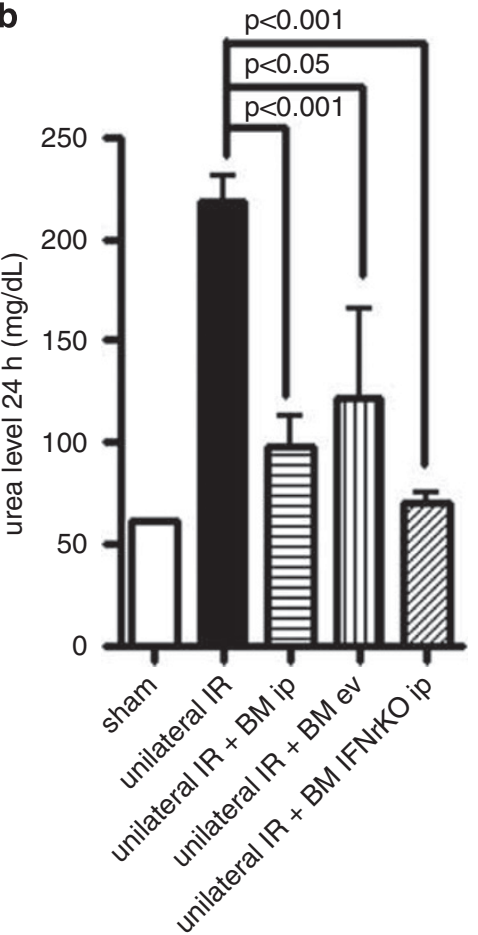

Untreated

$0.47 \pm 0.06 a$

$1.40 \pm 0.02 a, b$

$5.20 \pm 0.70 b$
BMMC IP treated

$0.65 \pm 0.13 a$

$1.55 \pm 0.11 \mathrm{a}$

$6.83 \pm 1.76$

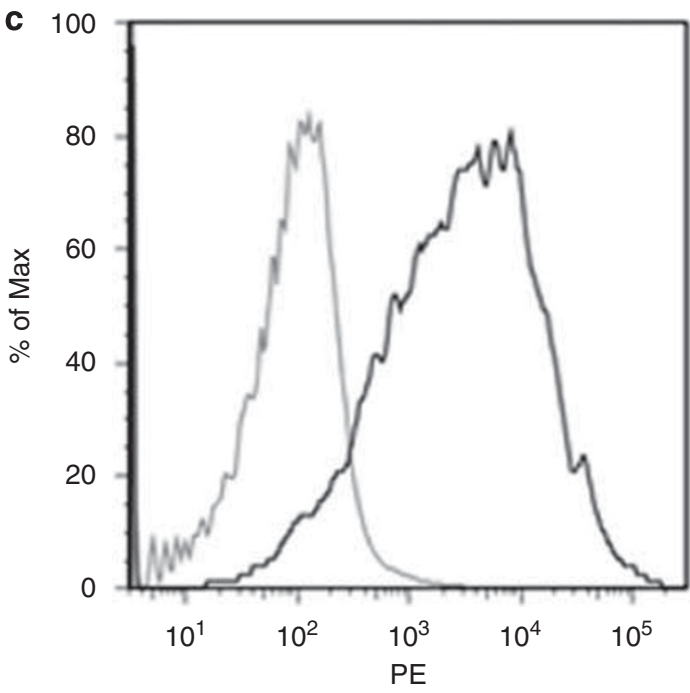

BMMC

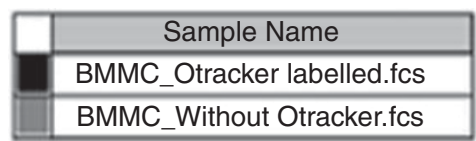

BMMC EV treated

$0.49 \pm 0.13$

$1.31 \pm 0.01 b$

$7.76 \pm 2.28 b$

Figure 2 Serum creatinine and urea levels after $24 \mathrm{~h}$ and BMMC tracking assay. C57/Bl6 mice were subjected to $1 \mathrm{~h}$ of IRI unilaterally. After $6 \mathrm{~h}$ of reperfusion, $1 \times 10^{6}$ cells were administered intraperitoneally (BM from C57/BI6 or from knockout animals for IFN receptor) or intravenously. After $24 \mathrm{~h}$, blood was collected to measure serum creatinine and urea. (a) Creatinine levels at $24 \mathrm{~h}$. (b) Urea levels at $24 \mathrm{~h}$. (c) Labeled cells with Qtracker. (d) Percentage of labeled cells found in the kidney, spleen and lung, analyzed by FACS.

of treated animals (Figure $5 \mathrm{~h}$ and i). These data correlated with immunohistochemistry for $\alpha$-SMA, vimentin and FSP-1, as shown in Figure 6.

\section{DISCUSSION}

A long-term follow-up study (1-10 years) with AKI patients revealed that approximately $12.5 \%$ were dialysis dependent and $19-31 \%$ had chronic kidney disease. ${ }^{31,32}$ This observation is still unrecognized by most clinicians. In renal transplantation settings, the negative long-term effect of AKI is more apparent. New strategies to promote better tissue response after ischemic events are therefore warranted.

In this study we showed that acute inflammation from severe AKI led to renal sclerosis. More interestingly, BMMC therapy immediately after the injury halted progression of this chronic fibrosis, mainly because of modulation of the inflammatory response. A single administration of whole bone marrow cells after the IRI led to improved functional parameters at $24 \mathrm{~h}$. In addition, modulation of kidney inflammation and systemic inflammation were observed. It is worth emphasizing that we observed a severe impairment in renal function at $24 \mathrm{~h}$. In this model, the contralateral kidney is left untouched, and less important renal function impairment should have been observed.

However, in this study we assume that the severe damages caused by $60 \mathrm{~min}$ of ischemia and a prolonged intraoperatory time could aggravate renal filtration function and ultimately harm the contralateral organ. As acute renal injury is an inflammatory systemic syndrome, circulating mediators, such as cytokines, could have affected the function in contralateral organ also. ${ }^{33,34}$ Distant organ damages after an AKI have been extensively studied. Not only organs can be injured, but also changes can be observed in brain, lung and liver. ${ }^{34-37}$

Decreased expression IL-6 (Th1 profile) and increased expression of IL-10 mRNA (Th2 profile) in kidney tissue after BMMC treatment were associated with a better functional outcome and show the important role of inflammation in AKI. Moreover, this modulation was systemic as expression of serum cytokines IL-12(p70), IL-5, TNF- $\alpha$ and IL-10 was also decreased. In this study our data show that BMMCs may lead to amelioration of inflammation, in situ or systemic, after IRI through downregulation of Th1cytokines and by promoting a Th2-based cytokine profile. ${ }^{38,39}$ 
a

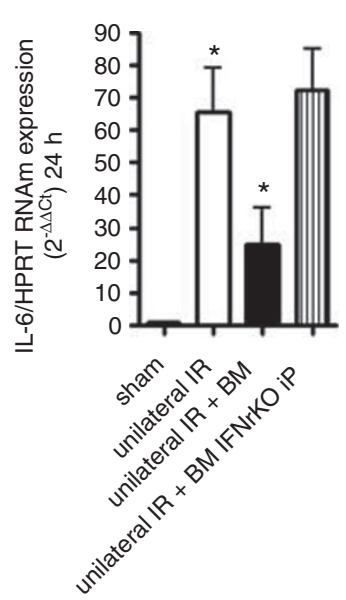

d

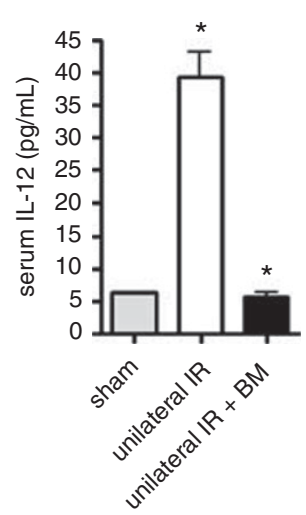

g

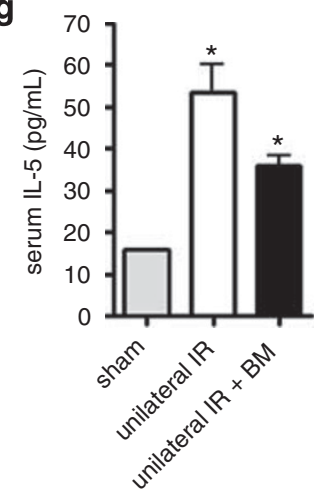

b

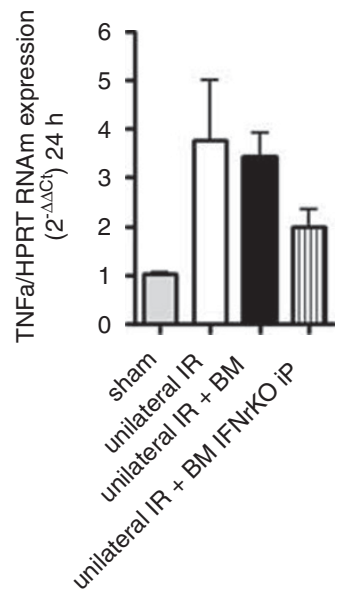

e

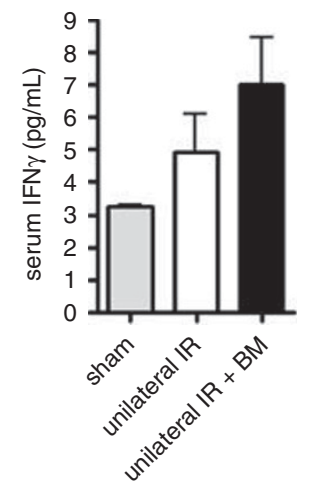

h

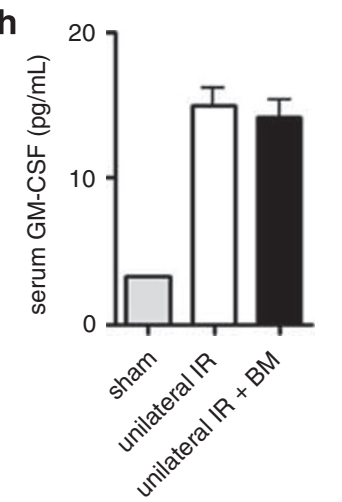

C

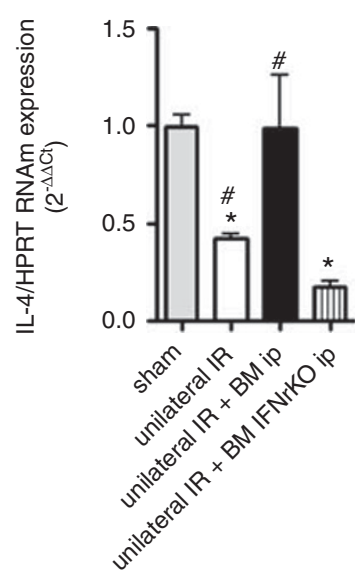

$\mathbf{f}$
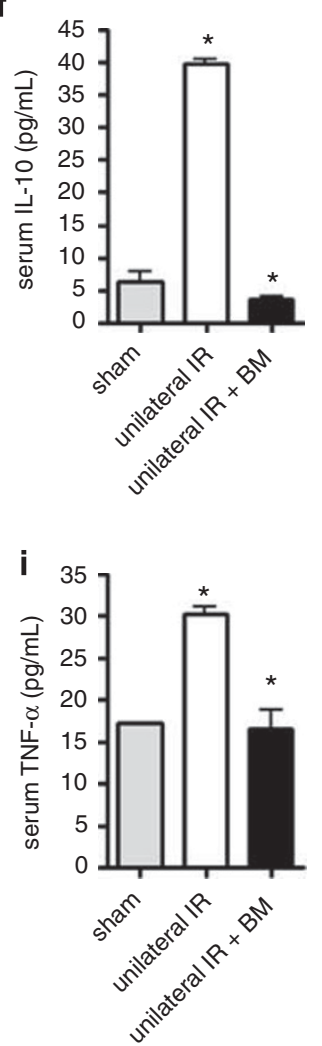

Figure 3 Tissue and serum cytokine expression in animals at $24 \mathrm{~h}$ after reperfusion. Gene expression in IRI kidneys of BM-treated and untreated animals, generated by referencing each gene to HPRT as an internal control. Fold changes vs sham animals. (a) IL-6 mRNA expression. (b) TNF- $\alpha$ mRNA expression. (c) IL-4 mRNA expression. Data expressed as mean of $2^{-\Delta \Delta C t} \pm$ s.d. ${ }^{*} P<0.05$. Serum was assayed for cytokine levels using a multiplex bead-based immunoassay kit. Serum cytokine levels for IL12 (p70) (d), IFN $\gamma$ (e), IL-10 (f), IL-5 (g), GM-CSF (h) and TNF- $\alpha$ (i) were determined in sham animals, animals subjected to unilateral severe ischemia-reperfusion (IR) injury and animals subjected to unilateral IR injury treated with whole bone marrow mononuclear cells (BMMCs). Data are expressed as mean \pm s.d.; $n=4$ mice/group. ${ }^{\star} P<0.05$.

Surprisingly, serum IL-5 expression after severe unilateral IRI was increased. This increase is probably correlated with the B-cell response after IRI. IL-5 helps B cells to become antibody-secreting plasma cells. Transgenic mice expressing the IL-5 gene show elevated levels of serum IgM, IgA and IgE; increased numbers of B-1 cells and eosinophils; and persis- tent eosinophilia. ${ }^{40}$ Several studies showed that the IgM isotype secreted by B cells is involved in IRI. ${ }^{41}$

The immunosuppressive properties of stem cells may be the key factor in this model. Particularly, from bone marrow cells, MSCs can suppress T-cell activation and also induce tolerance. ${ }^{42,43}$ The immune modulatory properties of MSCs 

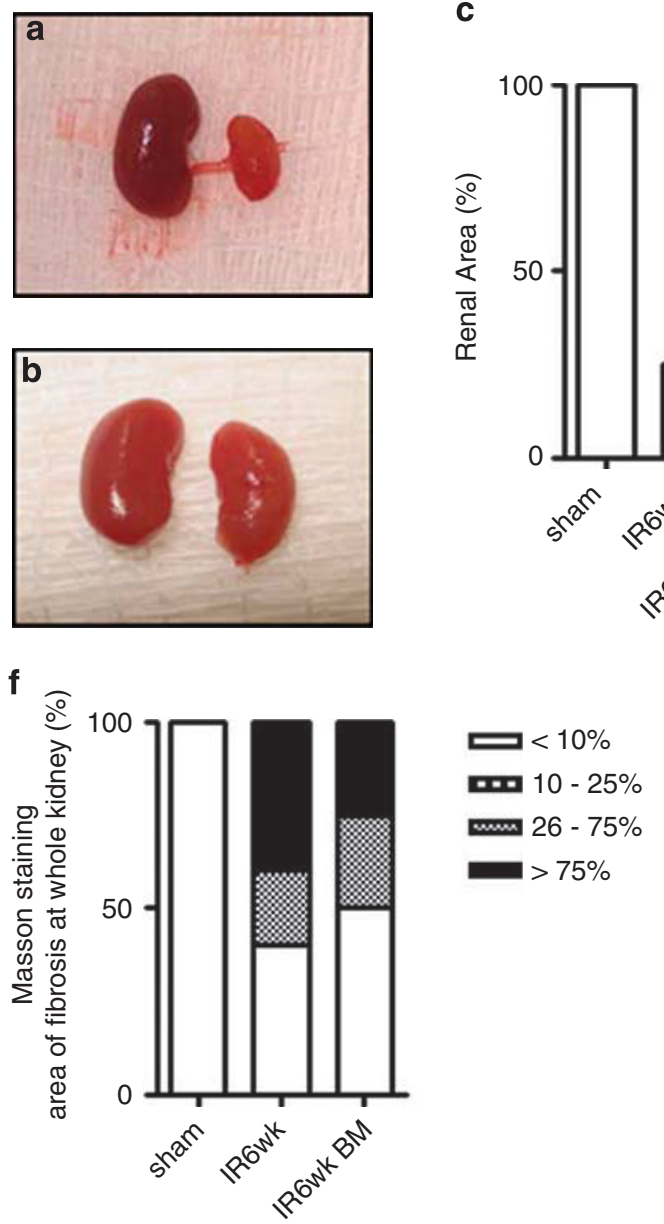

C

$$
\text { 응 }
$$
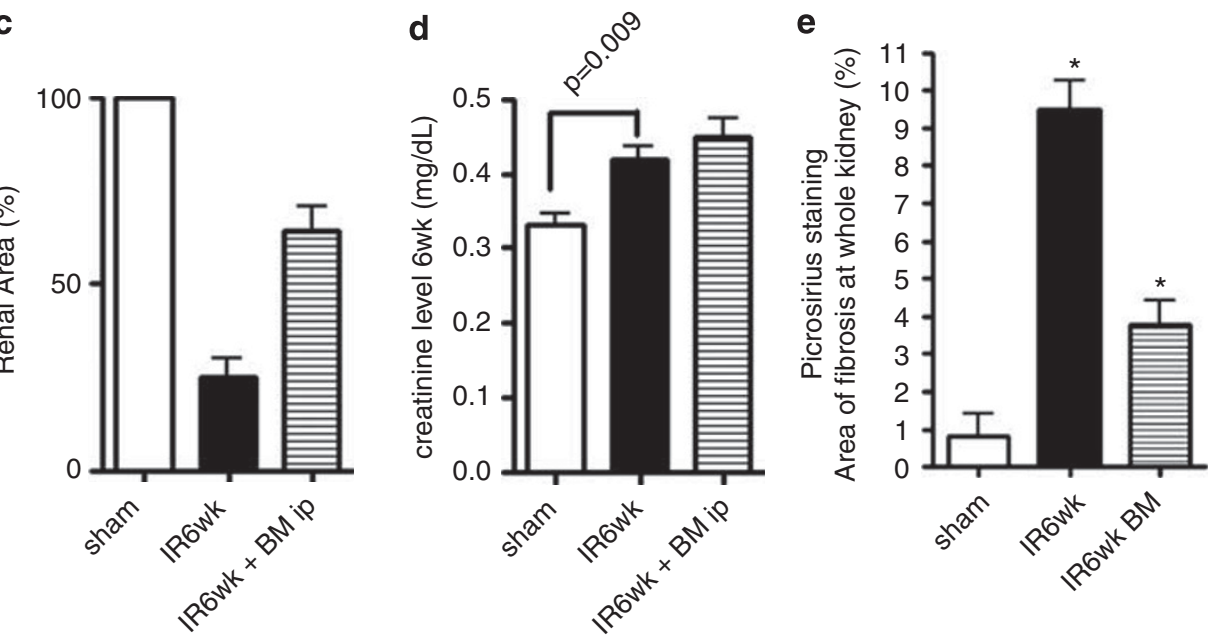

g

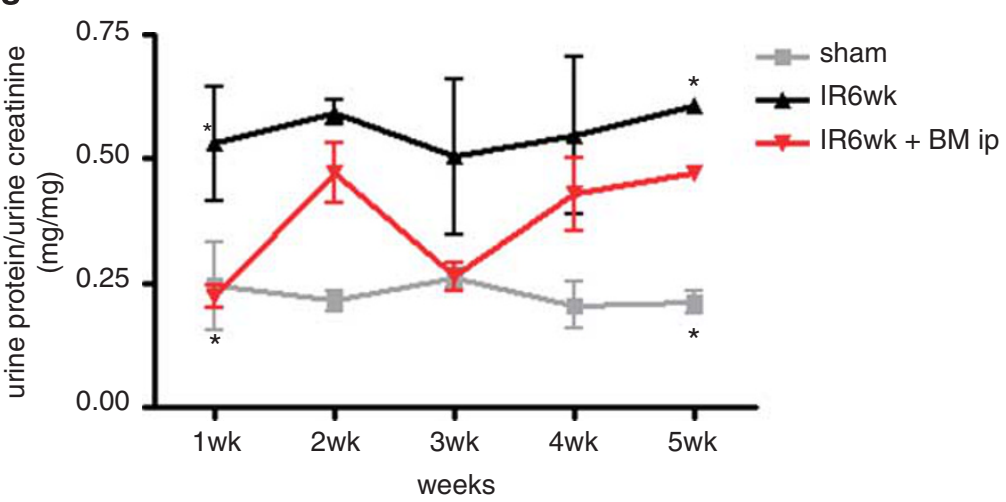

Figure 4 Macroscopic view of kidneys and functional parameters after 6 weeks of severe unilateral ischemia-reperfusion injury (IRI). (a) After 6 weeks, the left kidney subjected to severe unilateral IRI is reduced in size when compared with the contralateral kidney not subjected to IRI. (b) The left kidney was subjected to the same conditions in (a); however, after $6 \mathrm{~h}$ the animal was treated with the mononuclear fraction of bone marrow. (c) Renal area of all kidneys submitted to severe IR after 6 weeks. (d) Creatinine levels after 6 weeks. (e) Masson's trichrome staining was expressed as a percentage of the field area. (f) Picrosirius red staining was quantified by image analysis in NIS elements of Nikon. (g) Follow-up of proteinuria. For all groups, $n=5$. ${ }^{\star} P<0.05$. Results are shown as mean values \pm s.d. Abbreviations: 6 wk, 6 weeks; BMMC, bone marrow mononuclear cell; IR, ischemia-reperfusion injury.

have potential application as a novel immunosuppressive therapy for graft-versus-host disease (GVHD). The landmark article by Le Blancet $a l^{44}$ showed great results through 1 year of follow-up of GVHD patients treated with MSCs. The immune modulatory mechanisms of MSCs are still under investigation. Aggarwal and Pittenger ${ }^{45}$ showed that MSCs can interact with several immune cells and induce a stronger anti-inflammatory response by changing the cytokine secretion profile and increasing the proportion of $\mathrm{T}$ regulatory cells. PGE- $2,{ }^{45}$ TGF- $\beta,{ }^{46} \mathrm{HGF}^{47}$ inducible NO synthase $(\mathrm{iNOS})^{48}$ and $\mathrm{IDO}^{49}$ are the proposed mechanism to explain such properties. In AKI models, modulation of the inflammatory response leading to an increased Th2 response was also observed after treatment with MSCs, ${ }^{28,29}$ and was associated with a better outcome.

To show this immunomodulation by adult stem cell, we used a receptor IFN KO BMMC. We intend to show that without activation, BMMCs could not modulate inflammation. In fact, the immunomodulation observed by BMMC treatment was not observed in treatment with receptor IFN KO BMMC. Once BMMC is not activated, it does not secrete IDO 2,3 that can modulate T-cell proliferation. ${ }^{25}$ However, creatinine and urea levels were reduced. BMMC, without activation by IFN, can secrete other trophic factor that may regulate survival or apoptotic events, which are also present in the IRI event. ${ }^{27,50}$

The EMT is one of the sources of myofibroblasts in kidney fibrogenesis in animal models. ${ }^{51,52}$ Progressive graft dysfunction due to interstitial fibrosis and tubular atrophy (IF/ $\mathrm{TA}$ ) in the first year is a hallmark problem in kidney allografts. ${ }^{51,53,54}$ Primarily, TGF- $\beta$ is the molecule responsible for tubular epithelial cells changing their morphology to more mesenchymal cells. ${ }^{11,55}$ However, several studies have highlighted others signals that contribute to this transition, such as chronic hypoxia milieu, reactive oxygen species (ROS) and inflammation. ${ }^{56-58}$ IL-1- $\beta$ and TNF- $\alpha$, pro-inflammatory 
a
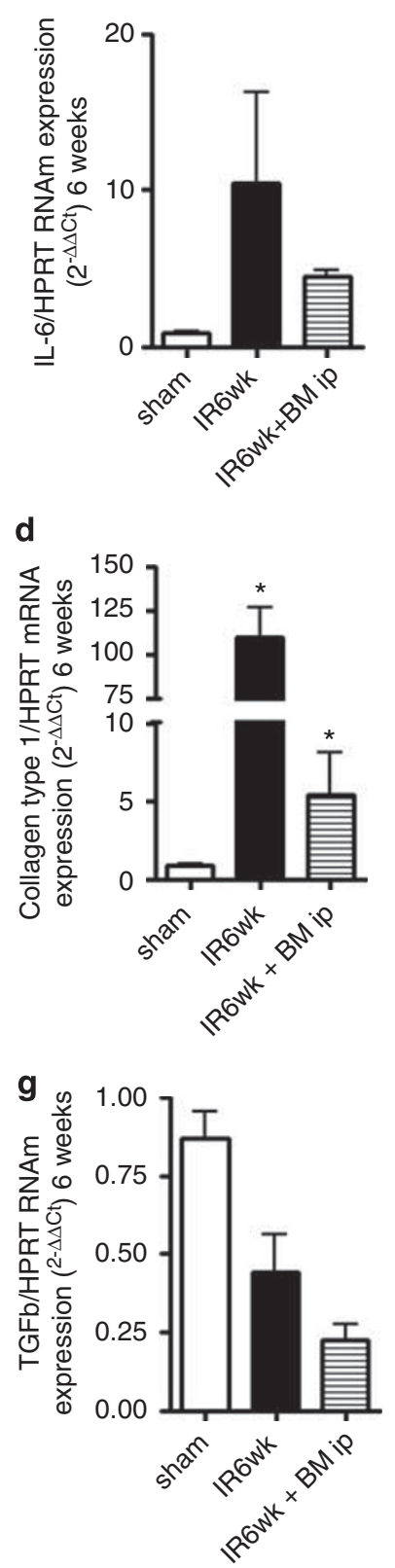

b
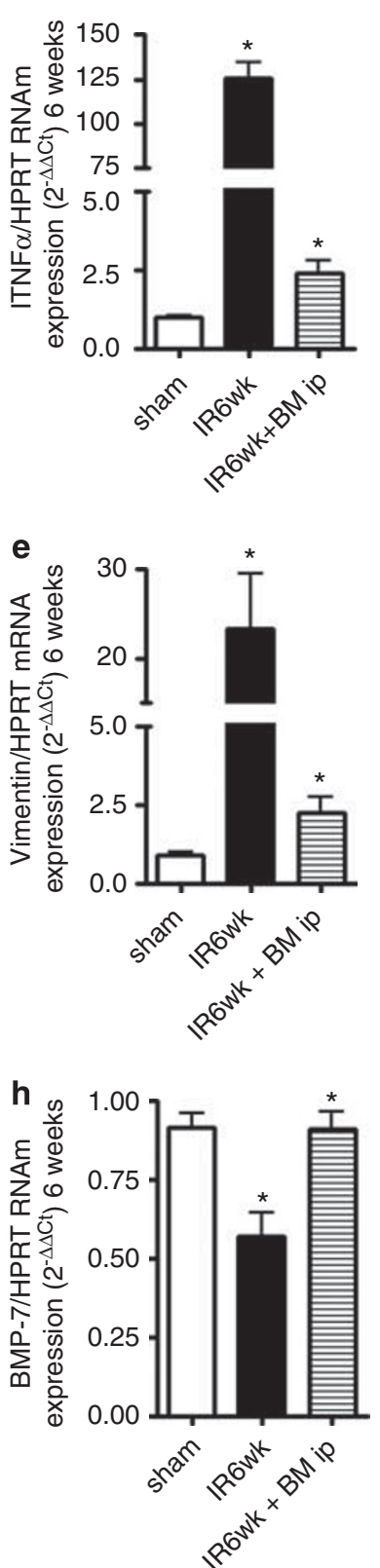

C
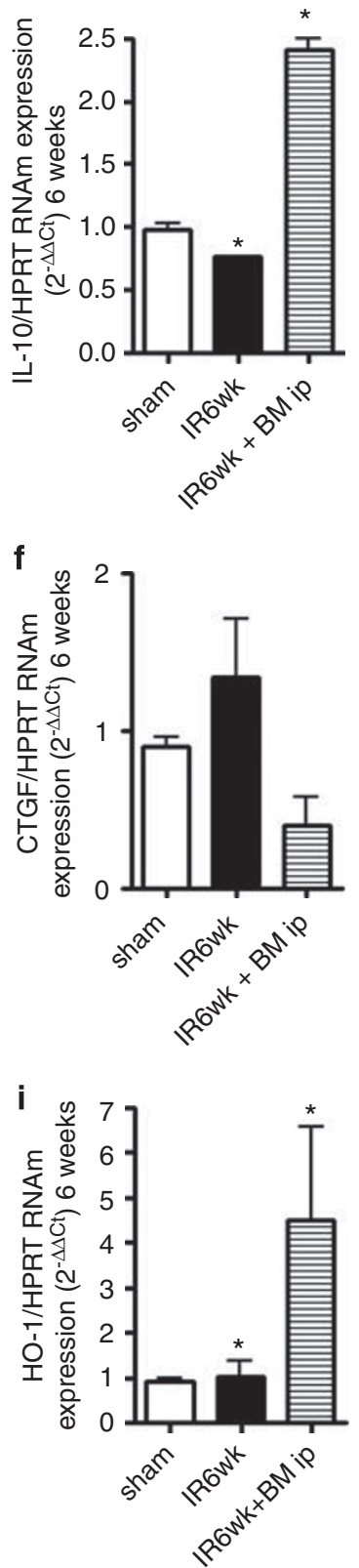

Figure 5 Cytokine, pro- and anti-fibrotic molecule mRNA expression in kidney tissue after 6 weeks of reperfusion. Gene expression in IR injured kidneys of BMtreated and untreated animals, generated by referencing each gene to HPRT as an internal control. Fold changes vs sham animals. (a) IL-6 mRNA expression. (b) TNF- $\alpha$ mRNA expression. (c) IL-10 mRNA expression. (d) Collagen type 1 mRNA expression. (e) Vimentin mRNA expression. (f) CTGF mRNA expression. (g) TGF- $\beta$ mRNA expression. (h) BMP-7 mRNA expression. (i) HO-1 mRNA expression. BM-treated animals (IR 6 weeks + BM) and untreated animals (IR 6 weeks). Data expressed as mean of $2^{-\Delta \Delta \mathrm{Ct}}$. For all groups, $n=5$. ${ }^{\star} P<0.05$. Results are shown as mean values \pm s.d. Abbreviations: CTGF, connective tissue growth factor; TGF- $\beta$, transforming growth factor- $\beta$; BMP-7 bone morphogenetic protein 7 ; HO-1, heme oxygenase 1 ; BM, bone marrow cells.

cytokines, seem to promote EMT. ${ }^{59-61}$ Moreover, in vitro studies have shown that immunosuppressive drugs are capable of inhibiting EMT. ${ }^{62}$ Thus, in our model the lower expression of pro-inflammatory cytokines in the early phase may protect the kidney from injury. This attenuation of injury at $24 \mathrm{~h}$ translates to a better outcome (less fibrosis and less inflammation in renal tissue) at 6 weeks when compared with untreated animals.
This early modulation of inflammation after a severe IRI, resulting from bone marrow stem cell administration, was even apparent in the long term in kidneys by the lower expression of pro-inflammatory cytokines and ultimately led to less fibrosis. All fibrotic molecules studied in our model (collagen I, vimentin, CTGF and TGF- $\beta$ ) were reduced in treated animals, indicating less fibrosis. Moreover, although we observed the decrease in fibrosis extension, the treated 


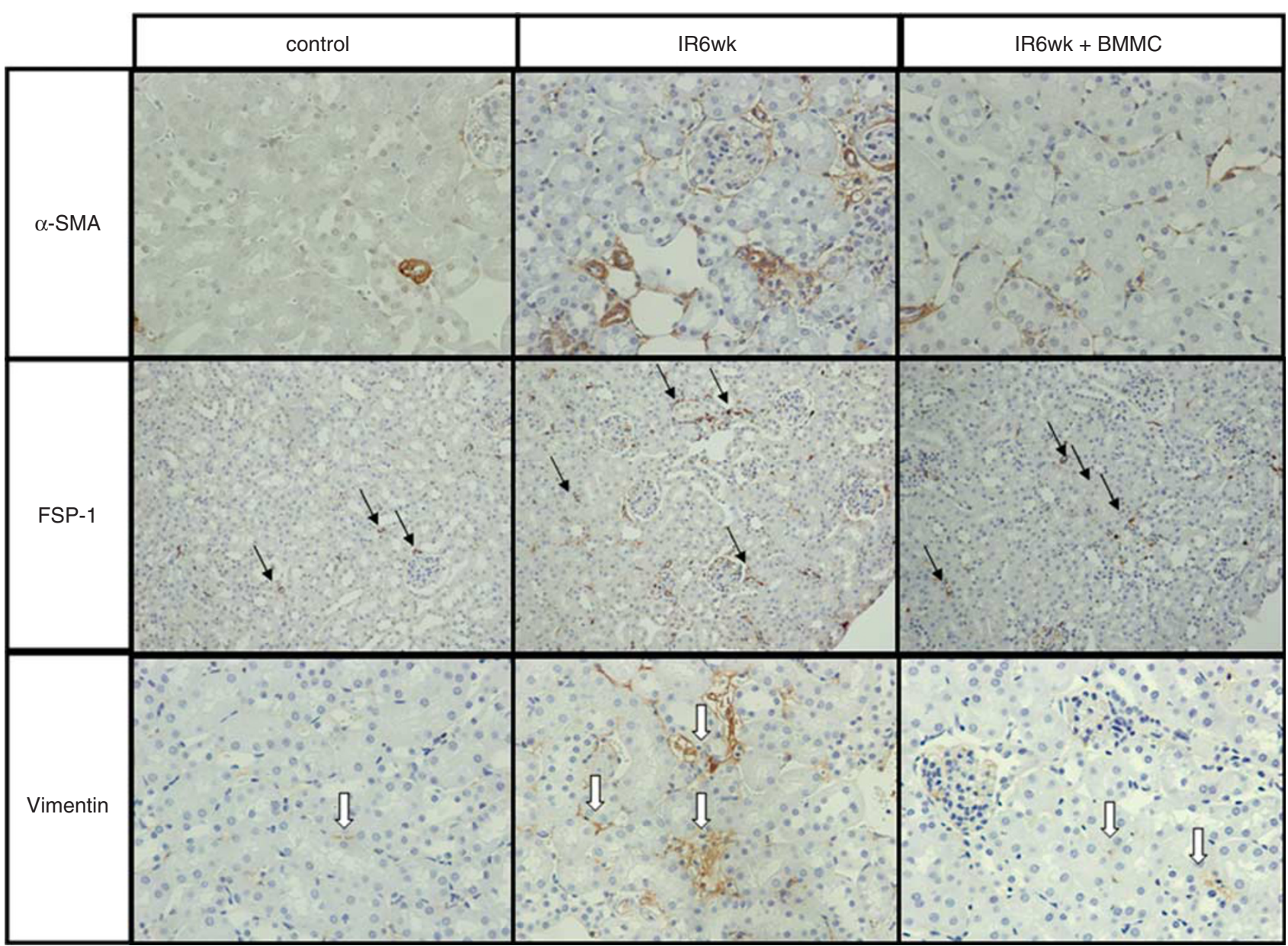

Figure 6 Representative photomicrograph illustrating $\alpha$-SMA, FSP1 and vimentin expression in renal tissue after 6 weeks. $\alpha$-SMA was well expressed in vessels (arrow); however, EMT led to $\alpha$-SMA expression in the tubular interstitial area. Magnification is $\times 40$. Greater numbers of FSP1 + cells accumulated in the interstitium of untreated animals than in MSC-treated animals. The magnification is $\times 20$. Vimentin is expressed between tubules (white arrow). After 6 weeks, vimentin amounts were higher in ischemic kidneys. With BMMC treatment, amounts were reduced. Magnification is $\times 40$.

animals had higher expression of BMP-7 and HO-1. In chronic inflammation, there is significant activation of the adaptive immune response due to significant mononuclear infiltration. Of the cytokines analyzed in kidney, IL-6 is decreased and IL-10 increased after BMMC treatment. Immunosuppressive properties of MSCs, present inside the BMMCs, may lead to the modulation observed in kidney after this treatment. Our group and others have already shown the modulation of inflammation after MSC treatment. ${ }^{27-29}$

Several groups showed evidence for BMP-7 as a potential antifibrotic agent in different models of renal disease. Renal BMP-7 disappears early in fibrogenic renal disease, which may facilitate its progression. BMP-7 improves maintenance of nephron function and structural integrity. ${ }^{63-70}$ BMMC treatment leads to increased expression of BMP-7, probably by inhibiting the progression of fibrosis. BMP-7 counteracts the action of TGF- $\beta$ in EMT, meaning that BMP-7 tends to preserve the epithelial phenotype. ${ }^{71}$ In our group, by working with the same model, we showed that BMP-7 mRNA expression was higher in animals pre-treated with cyclooxygenase inhibitor. ${ }^{72}$ The treated animals presented as less fibrotic with augmented BMP-7 expression.

$\mathrm{HO}-1$ was also expressed at higher levels after treatment. $\mathrm{HO}-1$ are the rate-limiting intracellular enzymes that degrade heme to biliverdin, CO, and free divalent iron. ${ }^{73}$ The role of HO-1 in renal fibrosis has been studied previously. ${ }^{74,75}$ Kie et $a l^{75}$ showed that HO- $1^{-1-}$ mice are prone to express TGF- $\beta$ on renal tubular cells, have increased macrophage infiltration and develop more fibrosis after unilateral ureteral obstruction.

In summary, amelioration of progression of renal disease in our experimental model was due to inhibition of early inflammatory events after IRI. Once the kidney was protected from early and intense inflammatory responses, the progression to fibrosis was attenuated.

\section{ACKNOWLEDGEMENT}

This work was supported by the Brazilian Foundation - FAPESP (Fundação de Apoio à Pesquisa do Estado de São Paulo), Grants Numbers: 06/00620-5, 04/08226-9, 07/07139-3), CNPq (04113826-5), INCT Complex Fluids and DECIT/Ministério da Saúde. 


\section{DISCLOSURE/CONFLICT OF INTEREST}

The authors declare no conflict of interest.

1. Morgera S, Schneider M, Neumayer HH. Long-term outcomes after acute kidney injury. Crit Care Med 2008;36(4 Suppl):S193-S197.

2. Najafian B, Kasiske BL. Chronic allograft nephropathy. Curr Opin Nephrol Hypertens 2008;17:149-155.

3. Nankivell BJ, Borrows RJ, Fung CL, et al. Delta analysis of posttransplantation tubulointerstitial damage. Transplantation 2004;78:434-441.

4. Fletcher JT, Nankivell BJ, Alexander SI. Chronic allograft nephropathy. Pediatr Nephrol 2009;24:1465-1471.

5. Burne-Taney MJ, Yokota N, Rabb $\mathrm{H}$. Persistent renal and extrarenal immune changes after severe ischemic injury. Kidney Int 2005;67:1002-1009.

6. Kalluri R, Neilson EG. Epithelial-mesenchymal transition and its implications for fibrosis. J Clin Invest 2003;112:1776-1784.

7. Lee JM, Dedhar S, Kalluri $R$, et al. The epithelial-mesenchymal transition: new insights in signaling, development, and disease. J Cell Biol 2006;172:973-981.

8. Zeisberg M, Kalluri R. Fibroblasts emerge via epithelial-mesenchymal transition in chronic kidney fibrosis. Front Biosci 2008;13:6991-6998.

9. Burns WC, Kantharidis P, Thomas MC. The role of tubular epithelialmesenchymal transition in progressive kidney disease. Cells Tissues Organs 2007; 185:222-231.

10. Gore-Hyer E, Shegogue D, Markiewicz M, et al. TGF-beta and CTGF have overlapping and distinct fibrogenic effects on human renal cells. Am J Physiol Renal Physiol 2002;283:F707-F716.

11. Cheng $\mathrm{O}$, Thuillier R, Sampson $\mathrm{E}$, et al. Connective tissue growth factor is a biomarker and mediator of kidney allograft fibrosis. Am J Transplant 2006;6:2292-2306.

12. Chatziantoniou C, Dussaule JC. Is kidney injury a reversible process? Curr Opin Nephrol Hypertens 2008;17:76-81.

13. Yang J, Dai C, Liu Y. Hepatocyte growth factor gene therapy and angiotensin II blockade synergistically attenuate renal interstitial fibrosis in mice. J Am Soc Nephrol 2002;13:2464-2477.

14. Nankivell BJ, Wavamunno MD, Borrows RJ, et al. Mycophenolate mofetil is associated with altered expression of chronic renal transplant histology. Am J Transplant 2007;7:366-376.

15. Bloudickova S, Rajnoch J, Lodererova A, et al. Mycophenolate mofetil ameliorates accelerated progressive nephropathy in rat. Kidney Blood Press Res 2006;29:60-66.

16. Utimura $\mathrm{R}$, Fujihara $\mathrm{CK}$, Mattar $\mathrm{AL}$, et al. Mycophenolate mofetil prevents the development of glomerular injury in experimental diabetes. Kidney Int 2003;63:209-216.

17. Zeisberg M, Bottiglio C, Kumar N, et al. Bone morphogenic protein-7 inhibits progression of chronic renal fibrosis associated with two genetic mouse models. Am J Physiol Renal Physiol 2003;285: F1060-F1067.

18. Mitu G, Hirschberg R. Bone morphogenetic protein-7 (BMP7) in chronic kidney disease. Front Biosci 2008;13:4726-4739.

19. de Zeeuw D, Lewis EJ, Remuzzi G, et al. Renoprotective effects of renin-angiotensin-system inhibitors. Lancet 2006;367:899-900; author reply -2 .

20. Remuzzi G, Ruggenenti P, Perico N. Chronic renal diseases: renoprotective benefits of renin-angiotensin system inhibition. Ann Intern Med 2002;136:604-615.

21. Bhagavati S. Stem cell based therapy for skeletal muscle diseases. Curr Stem Cell Res Ther 2008;3:219-228.

22. Roh JK, Jung KH, Chu K. Adult stem cell transplantation in stroke: its limitations and prospects. Curr Stem Cell Res Ther 2008;3:185-196.

23. Jing D, Parikh A, Canty JM, et al. Stem cells for heart cell therapies. Tissue Eng Part B Rev 2008;14:393-406.

24. English K, Barry FP, Field-Corbett CP, et al. IFN-gamma and TNF-alpha differentially regulate immunomodulation by murine mesenchymal stem cells. Immunol Lett 2007;110:91-100.

25. Krampera M, Cosmi L, Angeli R, et al. Role for interferon-gamma in the immunomodulatory activity of human bone marrow mesenchymal stem cells. Stem Cells 2006;24:386-398.

26. Liu KD, Brakeman PR. Renal repair and recovery. Crit Care Med 2008;36(4 Suppl):S187-S192.
27. Humphreys BD, Bonventre JV. Mesenchymal stem cells in acute kidney injury. Annu Rev Med 2008;59:311-325.

28. Togel $\mathrm{F}, \mathrm{Hu} \mathrm{Z}$, Weiss $\mathrm{K}$, et al. Administered mesenchymal stem cells protect against ischemic acute renal failure through differentiationindependent mechanisms. Am J Physiol Renal Physiol 2005;289: F31-F42.

29. Semedo $\mathrm{P}$, Wang PM, Andreucci TH, et al. Mesenchymal stem cells ameliorate tissue damages triggered by renal ischemia and reperfusion injury. Transplant Proc 2007;39:421-423.

30. Caldas HC, Fernandes IM, Gerbi F, et al. Effect of whole bone marrow cell infusion in the progression of experimental chronic renal failure. Transplant Proc 2008;40:853-855.

31. Goldberg R, Dennen P. Long-term outcomes of acute kidney injury. Adv Chronic Kidney Dis 2008;15:297-307.

32. Bell M. Acute kidney injury: new concepts, renal recovery. Nephron Clin Pract 2008;109:c224-c228.

33. Kinsey GR, Li L, Okusa MD. Inflammation in acute kidney injury. Nephron Exp Nephrol 2008;109:e102-e107.

34. Liu M, Liang Y, Chigurupati $S$, et al. Acute kidney injury leads to inflammation and functional changes in the brain. J Am Soc Nephrol 2008;19:1360-1370.

35. Scheel PJ, Liu M, Rabb H. Uremic lung: new insights into a forgotten condition. Kidney Int 2008;74:849-851.

36. Ko GJ, Rabb H, Hassoun HT. Kidney-lung crosstalk in the critically ill patient. Blood Purif 2009;28:75-83.

37. Kadkhodaee M, Golab F, Zahmatkesh $M$, et al. Effects of different periods of renal ischemia on liver as a remote organ. World $\mathrm{J}$ Gastroenterol 2009;15:1113-1118.

38. Goes N, Urmson J, Vincent D, et al. Acute renal injury in the interferongamma gene knockout mouse: effect on cytokine gene expression. Transplantation 1995;60:1560-1564.

39. Grigoryev DN, Liu M, Hassoun HT, et al. The local and systemic inflammatory transcriptome after acute kidney injury. J Am Soc Nephrol 2008;19:547-558.

40. Horikawa K, Takatsu K. Interleukin-5 regulates genes involved in B-cell terminal maturation. Immunology 2006;118:497-508.

41. Linfert $D$, Chowdhry $T$, Rabb H. Lymphocytes and ischemia-reperfusion injury. Transplant Rev (Orlando) 2009;23:1-10.

42. Rasmusson I. Immune modulation by mesenchymal stem cells. Exp Cell Res 2006;312:2169-2179.

43. Noel D, Djouad F, Bouffi C, et al. Multipotent mesenchymal stromal cells and immune tolerance. Leuk Lymphoma 2007;48:1283-1289.

44. Le Blanc K, Rasmusson I, Sundberg B, et al. Treatment of severe acute graft-versus-host disease with third party haploidentical mesenchymal stem cells. Lancet 2004;363:1439-1441.

45. Aggarwal S, Pittenger MF. Human mesenchymal stem cells modulate allogeneic immune cell responses. Blood 2005;105:1815-1822.

46. Di Nicola $M$, Carlo-Stella $C$, Magni $M$, et al. Human bone marrow stromal cells suppress T-lymphocyte proliferation induced by cellular or nonspecific mitogenic stimuli. Blood 2002;99:3838-3843.

47. Zhao ZG, Li WM, Chen ZC, et al. Immunosuppressive properties of mesenchymal stem cells derived from bone marrow of patients with chronic myeloid leukemia. Immunol Invest 2008;37:726-739.

48. Sato K, Ozaki K, Oh I, et al. Nitric oxide plays a critical role in suppression of T-cell proliferation by mesenchymal stem cells. Blood 2007; 109:228-234.

49. Meisel R, Zibert A, Laryea M, et al. Human bone marrow stromal cells inhibit allogeneic T-cell responses by indoleamine 2,3-dioxygenasemediated tryptophan degradation. Blood 2004;103:4619-4621.

50. Togel F, Westenfelder C. Adult bone marrow-derived stem cells for organ regeneration and repair. Dev Dyn 2007;236:3321-3331.

51. Vitalone MJ, O'Connell PJ, Jimenez-Vera E, et al. Epithelial-tomesenchymal transition in early transplant tubulointerstitial damage. J Am Soc Nephrol 2008;19:1571-1583.

52. Strutz FM. EMT and proteinuria as progression factors. Kidney Int 2008, Aug 20.

53. Maluf DG, Mas VR, Archer KJ, et al. Molecular pathways involved in loss of kidney graft function with tubular atrophy and interstitial fibrosis. Mol Med 2008;14:276-285.

54. Hertig A, Anglicheau D, Verine J, et al. Early epithelial phenotypic changes predict graft fibrosis. J Am Soc Nephrol 2008;19:1584-1591.

55. Fogo AB. Mechanisms of progression of chronic kidney disease. Pediatr Nephrol 2007;22:2011-2022. 
56. Liu X. Inflammatory cytokines augments TGF-beta1-induced epithelialmesenchymal transition in A549 cells by up-regulating TbetaR-I. Cell Motil Cytoskeleton 2008;65:935-944.

57. Higgins DF, Kimura K, Bernhardt WM, et al. Hypoxia promotes fibrogenesis in vivo via HIF-1 stimulation of epithelial-to-mesenchymal transition. J Clin Invest 2007;117:3810-3820.

58. Bedi S, Vidyasagar A, Djamali A. Epithelial-to-mesenchymal transition and chronic allograft tubulointerstitial fibrosis. Transplant Rev (Orlando) 2008;22:1-5.

59. Park W, Griffin M, Grande JP, et al. Molecular evidence of injury and inflammation in normal and fibrotic renal allografts one year posttransplant. Transplantation 2007;83:1466-1476.

60. Chuang MJ, Sun KH, Tang SJ, et al. Tumor-derived tumor necrosis factor-alpha promotes progression and epithelial-mesenchymal transition in renal cell carcinoma cells. Cancer Sci 2008;99:905-913.

61. Fan JM, Huang XR, Ng YY, et al. Interleukin-1 induces tubular epithelialmyofibroblast transdifferentiation through a transforming growth factor-beta1-dependent mechanism in vitro. Am J Kidney Dis 2001;37:820-831.

62. Copeland JW, Beaumont BW, Merrilees MJ, et al. Epithelial-tomesenchymal transition of human proximal tubular epithelial cells: effects of rapamycin, mycophenolate, cyclosporin, azathioprine, and methylprednisolone. Transplantation 2007;83:809-814.

63. De Petris L, Hruska KA, Chiechio S, et al. Bone morphogenetic protein-7 delays podocyte injury due to high glucose. Nephrol Dial Transplant 2007;22:3442-3450.

64. Dussaule JC, Chatziantoniou C. Reversal of renal disease: is it enough to inhibit the action of angiotensin II? Cell Death Differ 2007;14: 1343-1349.
65. Wang S, de Caestecker M, Kopp J, et al. Renal bone morphogenetic protein-7 protects against diabetic nephropathy. J Am Soc Nephrol 2006;17:2504-2512.

66. Zeisberg M. Bone morphogenic protein-7 and the kidney: current concepts and open questions. Nephrol Dial Transplant 2006;21:568-573.

67. Patel SR, Dressler GR. BMP7 signaling in renal development and disease. Trends Mol Med 2005;11:512-518.

68. Biyikli NK, Tugtepe H, Cakalagaoglu F, et al. Downregulation of the expression of bone morphogenetic protein 7 in experimental pyelonephritis. Pediatr Nephrol 2005;20:1230-1236.

69. Dube PH, Almanzar MM, Frazier KS, et al. Osteogenic protein-1: gene expression and treatment in rat remnant kidney model. Toxicol Pathol 2004;32:384-392.

70. Zeisberg M, Kalluri R. Reversal of experimental renal fibrosis by BMP7 provides insights into novel therapeutic strategies for chronic kidney disease. Pediatr Nephrol 2008;23:1395-1398.

71. Neilson EG. Setting a trap for tissue fibrosis. Nat Med 2005;11:373-374.

72. Feitoza CQ, Goncalves GM, Semedo P, et al. Inhibition of COX 1 and 2 prior to renal ischemia/reperfusion injury decreases the development of fibrosis. Mol Med 2008;14:724-730.

73. Camara NO, Soares MP. Heme oxygenase-1 (HO-1), a protective gene that prevents chronic graft dysfunction. Free Radic Biol Med 2005;38:426-435.

74. Kim JH, Yang Jl, Jung MH, et al. Heme oxygenase-1 protects rat kidney from ureteral obstruction via an antiapoptotic pathway. J Am Soc Nephrol 2006;17:1373-1381.

75. Kie JH, Kapturczak MH, Traylor A, et al. Heme oxygenase-1 deficiency promotes epithelial-mesenchymal transition and renal fibrosis. J Am Soc Nephrol 2008;19:1681-1691. 